\title{
Experience, Engagement and Social Interaction at a Steam Locomotive Multimodal Interactive Museum Exhibit
}

\author{
Loraine Clarke \\ University of Strathclyde. \\ 26 Richmond St, \\ Glasgow, G1 1XH, UK. \\ loraine.clarke@strath.ac.uk \\ Eva Hornecker ${ }^{1,2}$ \\ 1. University of Strathclyde. \\ 26 Richmond St, \\ Glasgow, G1 1XH, UK. \\ 2. Bauhaus Universität Weimar \\ Bauhausstr. 11 \\ D-99423 Weimar, Germany \\ eva@ehornecker.de
}

Copyright is held by the author/owner(s)

CHI 2013 Extended Abstracts, April 27-May 2, 2013, Paris, France.

ACM 978-1-4503-1952-2/13/04.

\begin{abstract}
This paper describes the on-going study of an

interactive multimodal museum exhibit about a steampowered locomotive at the Riverside Transport Museum in Glasgow, UK. We examine the role of multimodal interaction relating to effects on (1) visitors' experience of the exhibit, (2) engagement with the subject matter

(3) social interaction and (4) engagement with the exhibit itself. We discuss key questions of our study, a set of initial findings, reflections and future work.
\end{abstract}

\section{Author Keywords}

Museum; installation; multimodal interaction; collaboration; edutainment

\section{ACM Classification Keywords}

H.1.2. [Information Systems]: User/Machine Systems,- Human Factors. H.5.1.

\section{Introduction}

Interactive exhibits are strongly expected in traditional museums and cultural centers today. The presence of hands-on exhibits in science centers along with our familiarity of high quality media experiences in everyday life has increased our expectations of digital interactive exhibits in museums. Prior research has explored questions in the museum context relating to 
social interactions, 'hands-on' physical interaction, how people make sense of exhibits, visitor experience and 'minds-on' engagement [10, 1, 5, 7, 8]. However, as increased access to affordable technology is supporting the development of novel multimodal exhibits there is a need to question the value and effectiveness of multimodal interactive exhibits in the museum context.

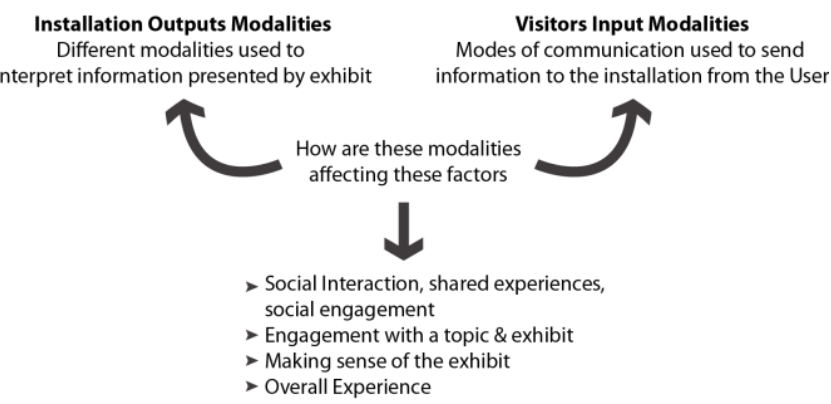

Figure 1. Overall Research Interests

We aim to understand the interaction that emerges around multimodal input and output channels between visitors and an exhibit and to develop in-depth

knowledge of how interaction with multimodal exhibits relates to (1) visitors' experience of an exhibit, (2) social interactions, (3) engagement with a topic and (4) the exhibit (figure 1 ). The research intends to examine installations considering the modes of communication between a visitor and the exhibit, investigating their integration with other modalities, the context, topic and target audience. We anticipate the research will contribute to a greater understanding of how different modes of communication with ICT relate to experiential qualities and engagement for users within museums and public spaces.
This paper details the ongoing study of a single interactive multimodal exhibit called the 'Glen Douglas' at the Riverside Transport Museum in Glasgow, UK. The exhibit has visitors making a simulation of a steam powered locomotive run by controlling coal, water and the steam levels.

\section{Installation Overview}

The Glen Douglas is a multimodal interactive exhibit designed to promote collaboration, hands-on learning and task-oriented learning with families in mind as the target audience. The exhibit runs alongside the real Glen Douglas steam locomotive in the museum. It consists of two interactive stations (figure 2) where visitors can add coal and water to the steam engine at station 1 and regulate the steam pressure in the engine at station 2, as well as a number of visual outputs representations and displays using different media (figure 3). The goal of the exhibit is to get the steam train running by monitoring the various media outputs and controlling the water, coal and steam levels. If successful, a physical wheel model moves at the far right end of the exhibit, and steam train noises appear. Typically, visitors add coal and water to the steam locomotive at station 1 (figure 2) using the lever and wheel while another person at station 2 (figure 2 ) reads instructions relating to the progress of the steam locomotive (eg. the balance of coal and water levels, visual outputs) and regulates the steam pressure.

\section{Research Questions}

Visitors may use a range of resources available to make meaning of an exhibit such as other people's actions, conversations, gestures as well as the installation feedback (eg. visual, audio, tactile, proprioception). Our study aims to explore in what way people utilise 
these resources, combining them to make meaning, how this relates to their experience of the exhibit and their engagement with the topic. As core aspects of the visitor experience we consider social interaction, role play, imagination, control, feedback, challenge,

enjoyment, accomplishment, meaningfulness and motivation, based on prior research investigating experience and engagement within and outside of the museum context $[2,3,6,7,9,10]$.

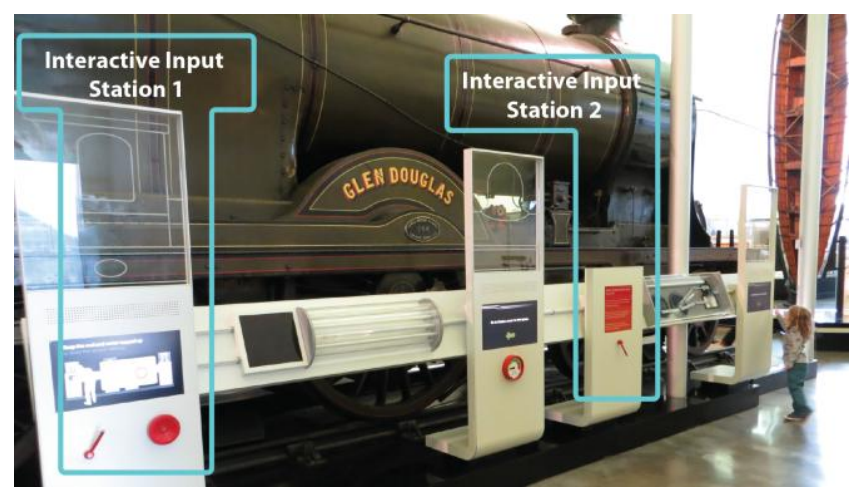

Figure 2. Overview of Glen Douglas Exhibit: Input areas

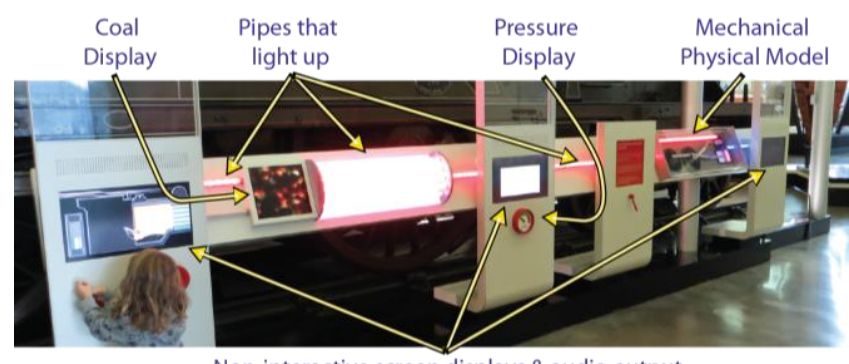

Non-interactive screen displays \& audio output

Figure 3. Overview of Glen Douglas Exhibit: output displays
Amongst other things, our study examines the modes of communication between people: seeing what others are doing, speaking, gesturing to each other, touching to stop one other or pointing. We further analyse the patterns of visitor behaviour concerning modalities between the digital media and visitors (touching, turning, running, gaining overviews, pausing, listening).

Detailed research questions entail, for example: What modes are encouraging or hindering social interaction? Does division of labour evolve where people take different roles, eg. directing others, observing? Do people intentionally share elements of the experience with others, eg. drawing somebody's attention to something they find interesting? What bodily movements and gestures emerge between the visitors and the exhibit and each other? Taking into account O'Brien and Toms work [6] which outlines four stages of engagement we intend to indentify these stages during interaction: (1) point of engagement, (2) sustained engagement, (3) disengagement and (4) reengagement and to determine whether these can be related to the exhibit's media and means of two way communication. We also aim to identify what seems to confuse visitors, and look for signs of challenge, motivation and accomplishment. The project plans to link these research questions to the various dynamic states of the installation modalities (e.g. screen output, audio output, pressure display, pipes display, input controls, etc.) in order to identify emerging patterns between the multimodal interaction and visitors' experience of the exhibit, (2) engagement with the subject matter, (3) social interaction and (4) engagement with the exhibit itself. 


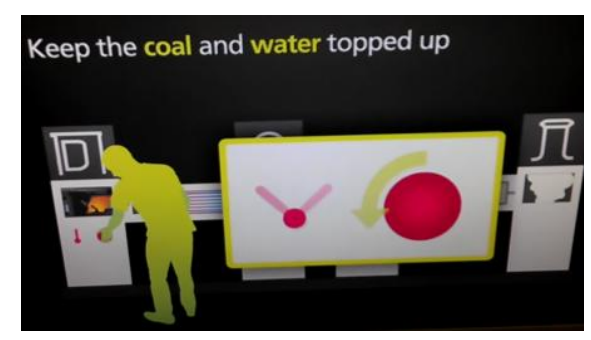

Figure 4. Initial Instructions

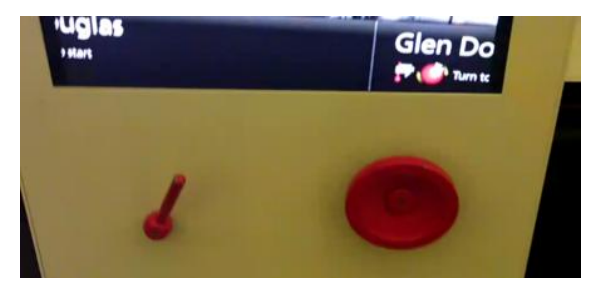

Figure 5. Coal lever and water whee controls at Station 1

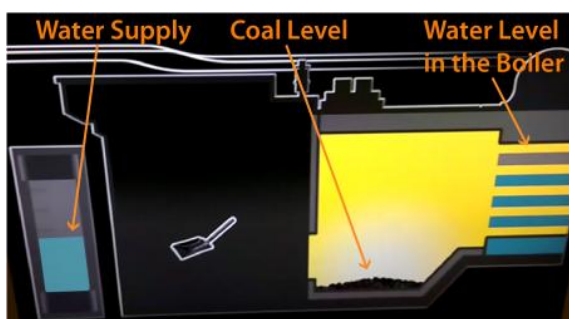

Figure 6. Water and Coal visual representations at station 1

\section{Study Description}

The initial stage of the study involved observations onsite (weekends and-days) of school tours and the general public, while creating detailed notes, sketches and photographs. These initial observations were collated to guide the direction of the study and the research questions discussed in the next section. In addition, a cooperative evaluation session with four participants was carried out. The second stage of the study entailed further focused observation, in addition to video recordings and a few open ended interviews with visitors after using the exhibit. This data awaits analysis. Approximately 6 hours of video data have been captured, using 4 cameras from different angles (focusing on different areas of the exhibit) along with audio recordings at both input stations.

Future work will involve detailed analysis of the observational data, interviews and audio-visual data, beginning with an open coding of videos followed by coding along categories still to be determined (visitor actions, events etc). We further plan to carry out interviews focusing on connections, visitors insights and findings that emerge from analysis of the data already gathered.

\section{Initial Findings and Future Questions}

The first stage of analysis focused on usability issues. We identified a number of issues in a co-operative evaluation session with a group of four adults, and confirmed these through observation of the general public and initial video analysis of the data. In a second stage of analysis we began to focus on social interaction and engagement with the subject matter and task. We here present our findings so far.
The layout of the overall exhibit shown in figure 2 runs along the length of the Glen Douglas steam locomotive which is positioned behind the exhibit to emphasize the size of the locomotive engine and the position of elements within the engine. However, the location of the pressure gauge display and lever in the centre of the exhibit isn't accurate to the real model, as they would have been positioned in the cab of the locomotive where drivers could control the pressure. Moreover, the mapping of input controls to the screen, which is directly above the controls at station 1

(figures,4 5 and 6), is not clear. Moving the lever adds coal and the wheel adds water. Both are red and unlabeled, and while the coal lever is on the left, on the screen display the coal level is depicted towards the right. With this left-right mix-up, no labels, and no clear physical affordances of the lever and wheel to suggest shoveling coal or adding water, visitors often initially struggle to understand what to do or make sense of the controls. In addition, feedback from the exhibition graphics (and the underlying simulation) seems to be delayed. When a person is prompted at station 2 "to add more water", and they add more water, it takes a long time for the visual feedback on the screens to react.

The exhibit is distributed over a large area. The screen at station 2 shows prompts to add coal or water, but the corresponding controls are at station 1 . Visitors at station 1 struggle to see the instructions presented at station 2, as well as to see the visual output at the other end of the exhibit where the mechanical physical model of the wheels is located (figure 7).

However, the exhibit was designed to encourage team work. From the initial findings there is evidence that 
the limited information at station 1 effectively encourages groups to work as a team, communicating instructions between stations 1 and 2 . When on their own, visitors tend to struggle with the exhibit. Yet for groups, the spatial separation of input and output modes encourages social interaction, providing a chance to engage socially, and to share an experience while using the exhibit and solving a task together. What may create difficulty for a solitary user may promote social interaction in a group situation [cf. 3]. This is clearly a trade-off in exhibit design.

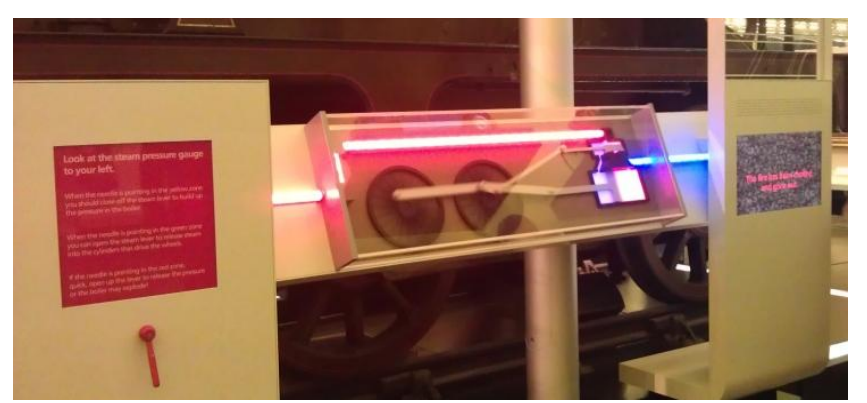

Figure 7. Close-up of the simulated wheels of the locomotive

Whether visitors explore the exhibit using 'mindless' hands-on interaction or take a more analytical way of interacting, they generally at some stage take a clear step back from the exhibit, gaining an overview of the overall exhibit and taking on a more observational role. This may indicate that people are taking a more analytic stance, thinking about the subject matter and/or the exhibit itself. We suspect this behaviour indicates a mindful connection with the subject matter, pondering aspects of the subject (one of our four key research interests). Future work will aim to find out what people are reflecting on at this stage.
Visitors sometimes end up interacting with the exhibit while other groups are using it as well. Most of the time, visitors will wait until others are finished, while observing and discussing. But occasionally cross-group collaboration emerges where visitors communicate instructions and feedback to each other working as a team. In general, cross-group interaction tends to be rare in museums, and thus is notable. Possibly, some people do not realize that the stations are part of one overall exhibit, or they are so focused on solving the task that they do not mind (especially since it is interaction over some physical distance, not encroaching social protocols of physical proximity). It appears that the different modes distributed over a large area provide accessibility to other visitors, increasing the chance of social interaction. Often external group members observe the actions of the current user and physically move up and down the exhibit looking at each representation.

Observation and initial review of the video data indicate that the phrases and words used by visitors in verbal communication are directly relevant to the workings of a steam locomotive, the subject matter. Thus, the exhibit appears to make users think about the process of what they are doing in relation to the subject matter, and thus to engage with the topic of the installation. Some visitors are extremely driven, spending up to 20 minutes at the exhibit. Furthermore, the exhibit presents a challenge to visitors, which has been linked to intrinsic motivation in a museum context [2].

There appear to be two main areas of the exhibit that visitors are attracted to, firstly station 1 where the coal lever and water wheel controls are placed and secondly the pressure lever combined with physical model output 
at the end of the exhibit. People in particular clustered around station 1 for most of their time at the exhibit, indicating the position with most control over the input.

\section{Reflections and Future Work}

Following these initial findings, the main point of interest from a research perspective is the positioning and spatial separation of directly connected input and output modalities. Observers who do not directly interact with the exhibit are included in our analysis since they are able to view user interactions as well as the reactions of the exhibit, attracting their attention and intellectual engagement with the exhibit prior to any physical interaction. Additionally, the layout of connected modalities encourages group members to communicate with each other from different areas, thus affecting social interaction. There is a noticeable amount of movement between different areas of the installation (going between 2 or more modalities). Further research on prior work relating to how embodied interaction affects experience and engagement is to be carried out.

Future work will involve detailed data analysis, focusing more on where in a visitor's interaction they specifically use certain modal resources, for example, the physical model output of the steam locomotive moving is perceived via our sense of vision but seeing the physical model moving nevertheless is different from just seeing wheels on a screen. We aim to explore the connections between these modalities, when visitors use them and what visitors reactions are. Ambiguity, surprise, anticipation and challenge are key aspects we would like to explore further, focusing on how multimodal interaction supports these.

\section{Acknowledgements}

We thank the Riverside Transport Museum staff for their support of the study and collaboration.

\section{References}

[1] Allen, S. Designs for Learning: Studying Science Museum Exhibits That Do More Than Entertain. Science Education, 88, 1 (2004), 17-33.

[2] Dindler, C., Iversen, O. L. Motivation in the Museum. Engaging Artifacts (2009).

[3] Hornecker, E. A Design Theme for Tangible Interaction: Embodied Facilitation. Prof of ECSCW' 05, Kluwer/Springer, (2005), 22-43.

[4] Hornecker, E. \& Stifter, M. Learning from Interactive Museum Installations About Interaction Design for Public Settings. Proc of OZCHI 2006, ACM Press, (2006).

[5] Humphrey, T. et al. Fostering Active Prolonged Engagement: The Art of Creating APE Exhibits. Left Coast Press, (2005).

[6] O'Brien, H., Toms, E. (2008). What is User Engagement? A Conceptual Framework for Defining User Engagement with Technology. JASIST, 59, 6 , (2008), 938-955.

[7] Pekarik, A. et al. Exploring Satisfying Experiences in Museums. Curator: The Museum Journal , 42, 2 (1999), 152-173.

[8] Vom Lehn, D., Heath, C. Accounting for New Technology in Museum Exhibitions. International Journal of Arts Management, 7, 3 (2005), 11-21.

[9] Vom Lehn, D., Heath, C., Hindmarsh, J. Exhibiting Interaction: Conduct and Collaboration in Museums and Galleries. Symbolic Interaction, 24, 2 (2001), 189-216.

Witcomb, A. Chapter 21. Interactivity Thinking Beyond Pedagogies. In A Companion to Museum Studies, Wiley-Blackwell (2006) 